\title{
Carcinogenesis Mechanism
}

National Cancer Institute

\section{Source}

National Cancer Institute. Carcinogenesis Mechanism. NCI Thesaurus. Code C18681.

Research concerned with the metabolism, toxicity, physiological disposition, and mechanisms of action of carcinogens and their metabolites. 